\title{
ALZHEIMER'S DISEASE THERAPEUTIC APPROACHES
}

\author{
SANDHYA A, GOMATHI KANNAYIRAM*
}

Department of Biotechnology, Dr. M.G.R. Educational and Research Institute, University, Chennai - 600 095, Tamil Nadu, India. Email: gomathi.sbt@drmgrdu.ac.in

Received: 03 February 2018, Revised and Accepted: 06 April 2018

\section{ABSTRACT}

A protein is a large biomolecule which consists of one or more chains of amino acid residues. Proteins exhibit a biological phenomenon in which, they are misfolded as aggregates (i.e., accumulate and clump together) either intra- or extracellularly. This process plays a central role in the pathogenesis of Alzheimer's disease (AD) and diabetes mellitus (DM) - 2 and common for many degenerative diseases. In this case, the histopathological consequences of protein misfolding such as sensile plaques and neurofibrillary tangles in AD and lewy bodies in Parkinson's disease occur. 8-10\% of adult population shares risk factors with AD. Amyloid fibrils which build up in tissue as an abnormal protein form Amyloidosis. Conformational change in three-dimensional structure forms amyloid fibrils. Type 2 DM is characterized by the deposition of islet amyloid polypeptide within beta cells of the pancreas which leads to chronic cerebral hypoperfusion that result in degeneration of neuroglial cells.

Keywords: Proteins, Misfolding, Alzheimer's disease, Type 2 diabetes mellitus, Neurofibrillary tangles, Amyloidosis, Parkinson's disease.

(C) 2018 The Authors. Published by Innovare Academic Sciences Pvt Ltd. This is an open access article under the CC BY license (http://creativecommons. org/licenses/by/4. 0/) DOI: http://dx.doi.org/10.22159/ajpcr.2018.v11i7.25104

\section{INTRODUCTION}

Major unsolved problems in biochemistry are protein folding. It has been recognized as the most critical obscure in the current century, because of the complex protein structure, which makes it difficult in predicting the folding patterns correctly [1]. Abnormal protein fibrils of extracellular fibrous amyloid deposits or intracellular inclusions are characterized to many neurodegenerative diseases, including Alzheimer's disease (AD), Parkinson's disease (PD), Huntington disease, and human prion diseases [2]. Conformational diseases are classified into a large number of disorders, which occurs due to conformational changes in the protein misfolding [3,4]. Many diseases can be further subdivided based on the hereditary inclusion body myositis. To monitor the formation of protein structure, there is a specific strategy that uses a battery of complementary stopped - flow and quenched - flow techniques. The other method involves the use of temperature jumps under cold denaturation conditions in which increase in temperature leads to refolding [5]. Amyloidosis and incomplete protein folding due to a minor error in the genetic blueprint are the two major classifications of protein folding disorders. AD patients have more number of amyloid plaques with degenerative nerve endings; the counts of the plaques are more in number when compared to the normal aging person's brain. This correlates with the type of mental impairment [7]. There are many flourished evidences stating that accumulation of proteins which are capable of forming amyloid deposits is the pathological mechanisms of illness $[8,9]$. In protein aggregation, monomers interact with dimers, oligomers, and insoluble fibrillar deposits.

The role of soluble oligomers in protein aggregation is beta-amyloid protein in $\mathrm{AD}$ and alpha-synuclein in PD [2]. Imbalance between amyloid beta production and its clearance results in the formation of neurofibrillary tangles (NFTs) containing tau proteins, synaptic and neuronal loss, and neuroinflammation [10]. As AD, Type 2 diabetes mellitus (T2DM) is a degenerative metabolic disease which occurs in older age; there will be a gradual loss of insulin secretion in pancreatic beta cells. According to the current records, about $96 \%$ of T2DM patients are diagnosed of this disease [12]. Based on the current understanding there are a lot of therapeutic and diagnostic approaches on amyloid beta protein and alpha-synuclein pathobiology. Alpha-synuclein is found in the human brain at the tips of nerve cells. Gene is located on chromosome 4 in humans with band range 89,724, 099 bp-89, 838, and $315 \mathrm{bp}$ [14]. Studies reveal that human alpha-synuclein is made up of 140 amino acids encoded by SNCA gene [6]. Similarly, research and elucidation of protein folding and aggregation in $\mathrm{AD}$ and T2DM have become the important focal points of pharmaceutical research, which enhances the probability of therapeutic and pharmacological tools for understanding.

As we know, neurodegeneration occurs due to the loss in function of neuron or neuron cell death. In all neurodegenerative diseases, the mechanism involved is a genetic mutation, in which repeat CAG triplet codes glutamine amino acid to form poly $Q$ tract [13]. This study is conducted in animal models such as nematode, fruit fly, nonhuman pirates, and mice [10]. Several neurodegenerative diseases are proteopathies caused by protein misfolding [7]. This topic is a review on the clinical manifestations, diagnosis, risk factors, and treatment which can reform certain symptoms of illness.

\section{WHAT IS AD? AND WHY IS IT CRIPPLING?}

Alzheimer's is the form of dementia, which means memory loss and other cognitive abilities [2]. In other words, it can be explained as progressive, degeneration of brain ailment which affects memory, behavior, and thinking. It is identified by Alois Alzheimer in the year 1906. There are about $60-80 \%$ dementia cases. In the UK, currently, 5.5 million of ages 65 are more prone to this disease. According to the report in 2005 more than 24 million people are affected worldwide; an increase with 4.6 million of new cases each year. In recent 2017 report, 5.5 million people are reported with Alzheimer's [15]. In India more than 4 million people suffer from dementia, Alzheimer's seems to be more common condition out of all who have been affected. In some statistical report, they found that Alzheimer's may set to become a triplet by 2050. Average duration of this disease is about 8 years but can past up to 20 years. The survival rate of the patient depends on the onset of the disease symptoms.

Early onsets of $\mathrm{AD}$ are the rarest that accounts only in $2 \%$ of cases approximately between the age group of 30 and 60 years. The occurrence is due to the genetic inheritance patterns in case of the later onset and due to high genetic predisposition which involves in gene polymorphisms [2]. Identifying the genetic factors that predispose AD is a much difficult process. 
There are three different stages in Alzheimer's - mild, moderate, and severe. Tau proteins stabilize microtubules which have a critical function in cell division and intracellular trafficking [5].

\section{NEUROPATHOLOGIC HALLMARK OF AD}

The Alzheimer is a syndrome of neuropathological hallmark. The changes that occur in the neuritic plaques shows to be the major mark of extracellular amyloid deposition and also the NFTs which acquire the intracellular accumulation of tau protein which is seem to be hyperphosphorylated (Fig. 3) [21]. The AD and PD are associated with defective tau proteins which lack the stabilizing capacity of microtubules. These tau proteins are the product of differential splicing from a single gene. In humans, it is designated as microtubule-associated protein tau which is located on chromosome 17 [5] and in mouse chromosome 11. Tau proteins are identified as heat stable proteins in 1975.

Large randomized clinical trials evaluate anti-amyloid and diseasebased therapies for the treatment and prevention of AD. This therapy utilizes imaging biomarkers. NFTs involved are known as Braak stages. In Pick's disease and corticobasal degeneration, tau proteins which stabilize microtubules are deposited as inclusion bodies within swollen neurons. Sometimes, the synuclein and tau protein interaction causes overlapping of tauopathies with synucleinopathies.

Amyloid precursor protein (APP) metabolic pathway. Neurobiological mechanisms involved in the pathogenesis of AD (Fig. 1).

Hence, the tau protein plays a major role in memory deficits in AD amyloidbeta alters the tau metabolism and leads to disease. Based on amyloid beta hypothesis, amyloid beta is derived from the APP by two aspartyl proteases: Beta- and gamma-secretases [16]. Beta-secretase cleaves APP to remove the larger ectodomain by leaving the c-terminal stub which is membrane bound. Concomitantly, gamma-secretase cleaves 99 amino acid stub and releases an amyloid beta [17]. Relying on the gamma-secretase, the amyloid beta comprises into 40 and 42 amino acid residues. Longer form of amyloid-beta which is prone to oligomerize forms fibrils resulting in the formation of amyloid beta 40 and 42 . When compared to amyloid beta 42 , amyloid beta 40 is involved in fibril formation, overproduction of amyloid beta 42 results in early onset of AD [18].

It is the primary structure of the $\beta$ - APP, comprising 770 amino acids. At the $\mathrm{N}$ terminal, 17 residue signal peptide occurs and two alternatively spliced exons of 56 and 19 amino acids are inserted at 289 residues containing serine protease inhibitor as the first domain of Kunitz type. 542 and 571 are found as $\mathrm{N}$ - glycosylation sites. The vertical orange bar contains membrane-spanning domain amino acids 700-723. The amyloid $\beta$ protein fragment is represented as a white box containing 28 residues, 12-14 residues are on the outer membrane as a transmembrane domain. The residue 687 is indicated with an arrow is a constitutive proteolytic cleavage which is made by unknown proteases designated as $\alpha$-secretase, which enables secretion of the large, soluble ectodomain of APP into the medium and the retention of the 83-residue carboxy-terminal fragment in the membrane which is approximately $10 \mathrm{kDa}$, this fragment can undergo cleavage at the residue 711 or 713 by unknown protease known as $\gamma$-secretase and releases the $\mathrm{p} 3$ peptides. The residue 671 is cleaved by an unknown proteolytic enzyme called as $\beta$-secretase, resulting in the secretion of truncated APP molecule which has the retention of 99-residue of approximately $12 \mathrm{kDa}$ (carboxyterminal fragment). Further, the cleavage of $12 \mathrm{kDa}$ fragment is carried by $\gamma$-secretase, which further releases $A \beta$ peptides. Besides age, the other genetic risk factors which are involved in the cause of $\mathrm{AD}$ is family history of dementia, rare dominantly-inherited mutations in the genes which impact amyloid in the brain and apolipoprotein E, epsilon 4 allele [20]. Certain other risk factors are acquired risk factors such as hypertension, lipoproteins, cerebrovascular disease, altered glucose metabolism, and brain trauma.

T2D and obesity associated with 1.5-fold increased the risk of AD. The areas of active investigation are relationship between insulin and amyloid beta metabolism and hyperinsulinemia and insulin resistance that have direct effects in the brain. Few studies suggest that insulindegrading enzyme metabolizes both amyloid beta and insulin and accumulates beta-amyloid [18]. There are many studies found to be associated with medications, e.g., benzodiazepines, anticholinergics, antihistamines, and opioids.

External brain examination conducted in Alzheimer's patients shows cortical atrophy, occurs in the limbic and cortices which are associated with them followed by the enlargement of lateral ventricles. This hallmark is diagnosed by silver staining and viewed under the microscope. The loss in neurons and pyramidal cells occur which includes the presence of intraneuronal NFTs and extracellular deposits of the amyloid filament. These are surrounded by the altered neuritic processes and glia known as sensile plaques.

In the majority of $\mathrm{AD}$ brains, sensile plaques accompany with the argyrophilic bundles of intraneuronal cytoplasmic fibers known as NFTs which are present in the cell bodies of neurons, the axons projects toward neuritic plaques region [19].

The brain parenchyma, along with arteries both cortical and meningeal, arterioles, and capillaries have many morphological $\mathrm{A} \beta$ proteins.

Modified Bielschowsky silver stain shows the histopathological lesions of AD. From a 69-year-old man with 6 years history of dementia $6 \mu \mathrm{m}$ paraffin section of the amygdala is obtained. The cytoplasmic space of pyramidal neurons is occupied by the NFTs which are darkly stained. The clear cytoplasmic space is occupied by the normal neurons (represented as arrows). The center region is sensile plaque which contains large and compacted deposits of extracellular amyloid (represented as A) surrounded by dystrophic neurites (represented as open arrows heads). Neuritic plaques contain altered axons and dendrites.

Pick's disease occurs when the non-Alzheimer's tauopathies get associated with frontotemporal dementia [11]. Extracellular amyloid plaques and NFTs show the presence of Alzheimer's in the brain [6]. They exhibit morphological and biochemical characteristics. Neurons bear NFTs, composed of hyperphosphorylated microtubules associated protein, known as tau [11]. Not only Alzheimer's are associated with NFTs but with other disorders which are not associated with cognitive dysfunction and memory impairment. Recent study stated that tau phosphorylation is the limiting factor in amyloid-beta-induced neurotoxicity.

The brain of Alzheimer's patient is characterized microscopically, by the extracellular amyloid plaques and intraneuronal NFTs. The numerous proteins in amyloid plaques have a broad range of morphological and biochemical characteristics $[47,48]$. Plaques those are diffused are not tending to be fibrillar and have $A \beta_{42}$. These are the immature deposits which are detected in the younger patient's brain along with Down's syndrome before $\mathrm{AD}$ manifestations. As a result of this, the diffuse plaques are considered to be the precursors to mature into neuritic plaques. Few plaques such as dilated, dystrophic neurites, activated microglia, and reactive astrocytes can be seen around the neuritic plaques [49].

AD involves risk factors such as modifiable and non-modifiable. Modifiable includes diet, supplementary intake, T2DM, mood, and hypertension whereas non-modifiable includes genes and family history. The major cause of AD is vascular factors. Smoking involves the cardiac risk, those who consume alcohol accumulates a lot of risk associated with brain atrophy and volume loss. Similarly, obesity leads to dementia and cerebral damage [50].

As we discussed above, there are many significant literature which supports every process and clearance of $A \beta$, which is found to be the major component of amyloid plaques [52-57]. As well when compared 
to brain the initiator process is a key component which leads to AD [58]. The APP exists in three isoforms APP695, APP751, and APP770, in which the former being the most abundant in neuronal cells [59]. We already know that APP cleaves and generates A $\beta$ forms. Those can be either nonamyloidogenic or amyloidogenic which are disease-related and depends on the protease. Later, the $\beta$-secretase BACE1 cleaves APP at its N terminus, exactly, between the residues M671 and D672. Simultaneously, $\gamma$-secretase complex which contains PS1 or PS2, nicastrin, anterior pharynx-defective-1and presenilin enhancer-2, cleaves the fragment which is bound to APP at the C-terminus that results in the monomeric generation of $A \beta$ peptides of different lengths (Fig. 2) [60,61]. A $\beta$ peptide undergoes oligomerization in AD. The pre-fibrillar aggregates of amyloid appear to be toxic than those amyloid which have been matured, as the former most one generates species that are reactive on the neuronal membranes which are subjected to oxidative stress $[62,63]$.

There is another key which leads to a pathologic feature of $\mathrm{AD}$, is tauopathy, even that also promotes oligomerization. Tau oligomers are the pathologic structures accompanies with the progression of $\mathrm{AD}$ in mouse models and have an important function in behavioral impairments and neurodegeneration [64-66]. Many reports suggested that higher toxicity of tau oligomers is compared with tau filaments, and known as precursors of tau filaments which has the potentiality for the cause of disease $[67,68]$.

Based on molecular mechanism $A \beta$ fibrillogenesis has been focused on numerous studies, the protein misfolding process and its aggregation are elucidated in those studies [69]. There runs a process known as the nucleation-dependent polymerization model, which develops small oligomers that, in turn, produces a core to catalyze protein misfolding. This model has two phases: One is the lag phase, and the other one is the elongation phase. The elongation phase is followed after lag phase [70].

\section{T2DM AND AD LINKAGE}

DM is a metabolic disorder, which shows higher blood glucose levels for a long period of time and loss of homeostasis (glucose). T1DM occurs due to the lack of insulin, whereas in T2DM there will be a demand of insulin in pancreatic $\beta$ cells which will be insufficient [71]. Those people, who suffer with T2DM, are prone of higher risk of vascular dysfunction, loss in vision, impairments of cognitive function and kidney function deficiencies which result in dialysis [72,73]. Same as non-directed donors, T2DM occurs at later age. There are certain biochemical defects in T2DM, which is a proteinous plaque that comprises of IAPP but in major T2DM patients they are found to be absent [74]. IAPP, a part of calcitonin - like a family of polypeptides and is seen in animal species. It does not form amyloid in all species, but they are amyloidogenic in humans. IAPP is a derived from an 89 aa pre-prohormone $[75,76]$.

There is a vast difference between amyloidogenic human IAPP, and the non-amyloidogenic rat polypeptide is the amino acid change will be at the $6^{\text {th }}$ position. Within the two terminal part of polypeptides, there occurs a conserved a region which is the main components and plays a key roles. The former part is known to get involved in activating the receptor, and the latter part binds in an antagonistic manner. There will a middle domain between these two parts differentiates the IAPP in different forms and is responsible for aggregation at different propensities. When considered a rat model, the IAPP comprises 3 prolines. The $\beta$-sheet formation gets affected by the proline and $\mathrm{N}$-methyl amino acids. The mid-region has a single point of mutation and a Ser20Gly substitute, which promotes the amyloid formation and causes $\beta$-cell death [77].

Patients with higher blood sugar level have their $\beta$ cells would secrete elevated levels of insulin along with the IAPP, and there will be shift in lipid metabolism, that converts the excess amount of glucose into lipids, which would stress the system. The excess free radicals provide the ability to disrupt the charge and further the confirmation of the native proteins and the mechanism of clearance, therefore, the folding and modifying would turn to be a pathological role from the physiological $[78,80]$.
The most prevalent problem in aged people is AD and T2DM. As discussed, the cerebral $A \beta$ accumulation is the pathological hallmark in the $\mathrm{AD}$ [81], it is because of the deposition of the different polypeptide, known as amylin, that gives in the $\beta$-sheet formation and self-aggregation in the pancreas, mainly within the $\beta$-cells, of T2DM [82]. Many studies have reported that T2DM causes pathological angiogenesis and immature vascularization [83]. In some, it even leads to chronic cerebral hypoperfusion results in neuro-glial dysfunction and also degeneration [84]. Many suffering from T2DM are prone to attacks, often silent produces major consequences such as dementia and other long-term problems [85]. This kind of dementia accompanies in vascular dysfunction and known as a vascular cognitive impairment [86]. A $\beta$ in the normal brain of a person is dispersed in an excitation-dependent manner and have many physiological functions $[87,88]$. If we have a healthy vascular system, it will aid in proper function, but it will be critical when oligomerization and deposition of $A \beta$ starts. Neuroinflammation along with the process of seeding and spread is initiated eventually with neuronal dysfunction, and toxicity ensue [89]. With the event of insulin resistance, defective insulin signaling, and also the mitochondrial dysfunction in the brain, which are the common quirk of T2DM and AD; hamming the questions which one leads the other in the aged people [90-92].

Genetic linkage studies are identified as an $\mathrm{AD}$ that is susceptible to locus on chromosome 19 which is been shown in the ApoE gene [94]. Normally, in man, ApoE gene exhibits in three polymorphisms and some population studies demonstrate that there is an increase in the frequency of the E4 isoform in many AD patients [95].

\section{TAUOPATHIES ROLE IN AD}

Some studies suggest that tau is a microtubule-associated protein, which undergoes $n$ number of functions for stabilizing the tubulin dimers, consolidating both axons and dendrites $[96,97]$. Tau deposit disorders and are classified as primary tauopathies and secondary tauopathies. In primary tauopathies, the first pathology is the tau deposition, whereas in secondary tauopathies the pathology is the response of some other tau deposit [98].

\section{DIAGNOSTIC METHODS OF AD}

There is no specific test which confirms the Alzheimer's in the people. Certain diagnostic methods such as physical examination along with the mental status and neuropsychological testing are the first line treatment that can be given to the patients with AD. The disease prevention is inevitable. Therefore, the progress is measured using mini mental scale examination and Montreal Cognitive Assessment (MoCA) and clinical dementia rating scale. The measurements obtained from such scales are not so linear and showed a decline in the studies of the patients. Many clinicians use the standardized mental scale for the measurement, but compared to all MoCA with cutoff score 26 is widely used for the measurement of the patients mental status due to its sensitiveness for execution and language dysfunction.

Few diagnostic tools such as the brain imaging techniques - magnetic resonance imaging (MRI), computed tomography, positron emission tomography (PET), and cerebrospinal fluid (CSF) are currently used which may enable doctors to detect any specific changes caused due to AD. Brain MRI can document the structural diseases and the regional frontotemporal dementia. In case of structural MRI, the findings include focal atrophy and white matter lesions [21]. As these findings are nonspecific, the hippocampal volumes are considered to be the focal findings of the $\mathrm{AD}$ patients, because the hippocampal volume decline in normal aging and provides an evident support to the AD patients [24].

Nowadays, the $\mathrm{AD}$ neuroimaging is made available with the help of the hippocampal volumetry using age-related norms. The distinct region of the low metabolism and hypoperfusion of $\mathrm{AD}$ patients are revealed by functional brain imaging with fluorodeoxyglucose PET, functional MRI, and perfusion MRI [21]. Amyloid PET tracers such as 
F18 - florbetapir, F18 - flutemetamol, and F18 - florbetaben are used to measure the amyloid lesion burden in the brain which is aided to be the tool to diagnose $\mathrm{AD}$ in vivo and progresses the development of the antiamyloid drugs which help to differentiate $\mathrm{AD}$ from dementia.

Certain biomarkers which are not used in routine diagnostics play a major role in supporting $\mathrm{AD}$ by investigating the molecular and degenerative process. Low CSF A $\beta 42$, positive amyloid PET imaging using one of the amyloid PET tracers is the molecular biomarkers of $\mathrm{A} \beta$ protein deposition [22]. Biomarkers of tau deposition which is a key component of NFTs are increased CSF total tau and phospho tau and evidence of cerebral tau using a tau-specific PET tracer which is in development. Topographic biomarkers are used to assess the downstream brain changes which correlate with the neuronal dysfunction and neuronal death which associates AD [23]

Certain lab tests are recommended by the clinicians such as hypothyroidism and Vitamin B12 deficiency. Testing for infectious diseases such as syphilis and human immunodeficiency virus should be collected under suitable clinical circumstances. Mostly, PET allows visualizing the metabolism in most of the brain regions using ${ }^{18} \mathrm{~F}-2$ deoxy-2-fluoro-D-glucose (FDG) which serves as a surrogate marker of glucose metabolism. In some patients, early $\mathrm{AD}$ decreases the metabolism in parietal-temporal associates with the cortex and the cingulate gyrus and some marked changes in the medial temporal region and parietal-temporal that associates with cortex are detected. In abnormal PET-FDG is marked in the frontal which is associated with cortex. In accordance with the changes that are detected in regional cerebral perfusion by a single photon emission that computes with SPECT and can distinguish mild $\mathrm{AD}$ and various form of vascular dementia [99].

In recent research, they developed a thioflavin $\mathrm{T}$ analog, which is a Pittsburgh compound-B (PIB) compound B, which binds to $\beta$-sheet that is rich in fibrils. This compound crosses blood-brain barrier and binds to amyloid deposits in the brain parenchyma. This result in detecting the Carbon-11 which is labeled with PIB [100].

\section{THERAPEUTIC APPROACHES IN AD CASES}

Different therapeutic approaches for the treatment of AD (Fig. 4).

\section{Cholinesterase inhibitor}

The cholinesterase inhibitors and memantine are the widely used treatments that are made available for the patients. It is a symptomatic medication for the cognition and global functioning in patients. The inhibitor targets the acetylcholine deficit and raises the loss of neurons in the nucleus basalis of Meynert. In majority cases, the patients who are diagnosed with $\mathrm{AD}$ are offered with symptomatic treatment (cholinesterase inhibitors) which is been conducted as a trial of treatment. It is suggested to most of the patients with dementia and with lewy bodies and has greater benefits in patients. The degree of benefit using cholinesterase inhibitors is studied in the patients of various severities [25-27].

\begin{tabular}{llll}
\hline Stages of dementia & MMSE & MoCA & CDR \\
\hline Mild & $19-26$ & $12-16$ & 1 \\
Moderate & $10-18$ & $4-11$ & 2 \\
Severe & $<10$ & $<4$ & 3 \\
\hline
\end{tabular}

CDR: Clinical dementia rating, MoCA: Montreal cognitive assessment, MMSE: Mini-mental state examination

The relative effects of the cholinesterase inhibitors appear to be similar with the severe dementia patients. In earlier stages, short-term trails using donepezil or galantamine are used in moderate to advanced dementia. Donepezil, galantamine, and rivastigmine are the three different variety formulations of cholinesterase inhibitors. Donepezil hydrochloride $5 \mathrm{mg}$ daily at first and then $10 \mathrm{mg}$ daily; rivastigmine $1.5 \mathrm{mg}$ twice daily at first; and then $6 \mathrm{mg}$ twice daily; galantamine $4 \mathrm{mg}$

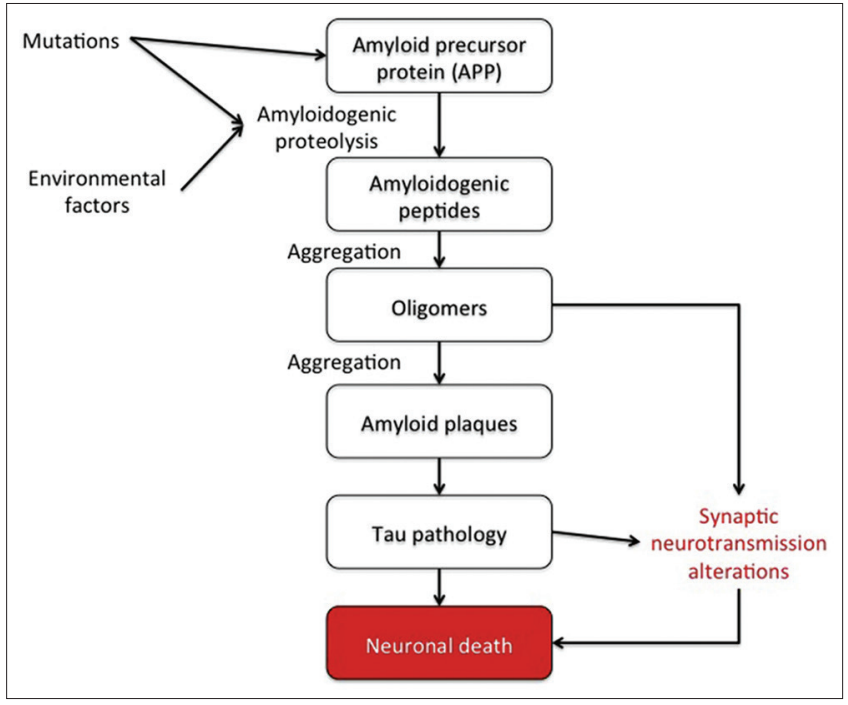

Fig. 1: Obtained from international journal of gerontology "new therapeutic targets in Alzheimer's disease"

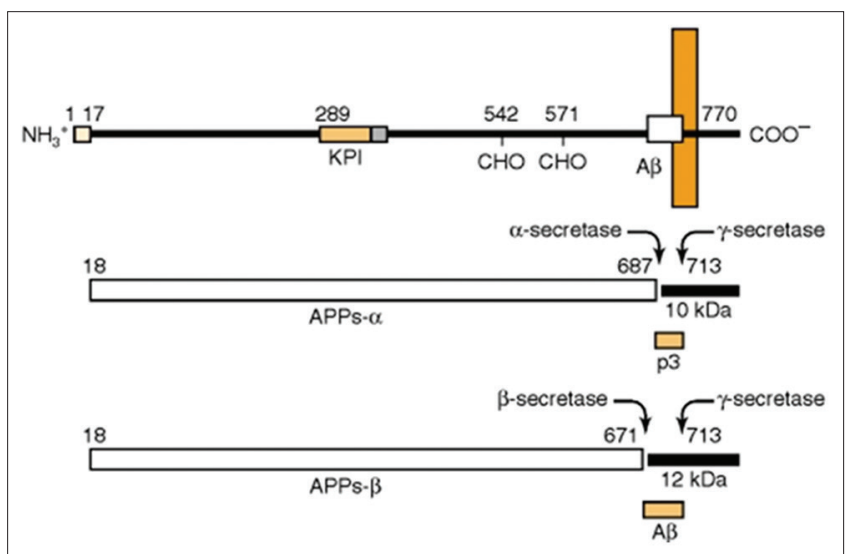

Fig. 2: Obtained from NCBI article "Alzheimer's disease is the most common neurodegenerative disorder"

twice daily; and then $12 \mathrm{mg}$ twice daily. Recent studies indicate that donepezil reduces memory and cognitive loss during early for several months $[28,29]$. The cholinesterase inhibitor provides clinical benefit only when the patients exhibit behavioral and psychological symptoms, and it is not found to be the preventive measure.

\section{Memantine}

FDA approved memantine, an antagonist for treating moderately advanced AD. It reduces the potential of glutamatergic excitotoxicity. The drug is prescribed as $5 \mathrm{mg}$ daily and increased to $5 \mathrm{mg}$ twice daily and then to $10 \mathrm{mg}$ twice daily. A studied showed that the patients are taking stable doses of donepezil, memantine had better outcome. However, these appropriate results show to be better outcome only when it is administered with cholinesterase inhibitor [30].

\section{Hormone replacement therapy}

According to the report given by women's health initiative study of estrogen and medroxyprogesterone in a postmenopausal women have higher chance of dementia. Estrogen therapy has adverse effect in women aged 65 years [31]. Similarly, it is found that estrogen therapy alone did not reduce dementia or incidence of mild cognitive impairment, but it also increases the risk of both conditions in a combined form. Therefore, hormone therapy used to prevent dementia showed a decline rate in 65 years women or older and is not recommended [32]. 


\section{Antioxidants}

A randomized study was conducted using selegiline, Vitamin E, and both together in patients with $\mathrm{AD}$ and compared with placebo [33]. This trial showed a positive result when compared to placebo. One of the other studies stated that Vitamin E at 2000 international units a day slows the progress of the disease. Cochrane dementia group register of clinical trials found that there is no sufficient evidence for the efficacy of Vitamin E in the AD treatment [34].

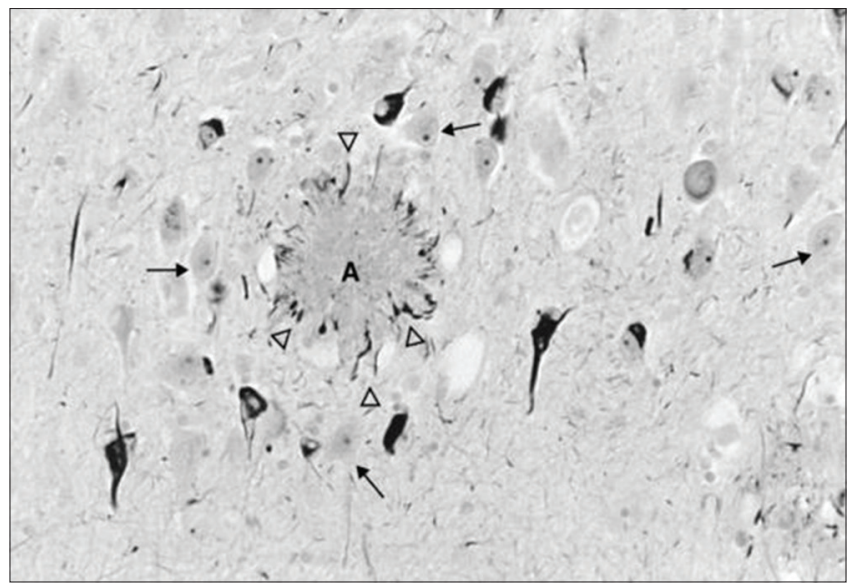

Fig. 3: Obtained from "Alzheimer's disease is the most common neurodegenerative disorder"

\section{Anti-inflammatory drugs}

AD patients have minor cellular signs of inflammation, increased cytokines and interleukins. The anti-inflammatory drugs such as naproxen and rofecoxib resulted with 1 year change in $\mathrm{AD}$ assessment scale-cognitive subscale score. These drugs did not reduce the cognitive loss. Since the drugs resulted in failure, clinical trial with an antiinflammatory agent is still an incomplete finding $[35,36]$

\section{Cholesterol lowering therapy}

Statins, HMG CoA is the reductase inhibitors, for preventing AD. HMG CoA has a low risk of developing dementia. A randomized trial with statins was conducted by simvastatin or atorvastatin in hypercholesterolemia patients. Using this drug plasma level of $A \beta 40$ and $A \beta 42$ is measured. Both stains reduced $56 \%$ of plasma levels but the levels of $A \beta 40, A \beta 42$, and total $A \beta$ unchanged. These studies did not support the effect of statins and alter the APP processing in humans $[37,38]$

\section{Vaccination}

$A \beta 42$ is given as monthly immunization for 11 months, prevents the $A \beta$ plaque formation, neuritic dystrophy, and astrogliosis. The astrogliosis in mice is transferred with V717F human APP gene which is mutant. The $A \beta 42$ generates antibodies, recognizes $A \beta$ plaques, diffuse $A \beta$ deposits, and vascular $A \beta$ in blood vessels of brain. This concludes that A $\beta 42$ have higher degree of selection which targets the pathogenic structures.

Even though $\mathrm{A} \beta 42$ revealed itself to be a positive therapeutic effect, they induced the immunized patients to develop autoimmune meningoencephalitis. In some cases, the brain of people having mild to

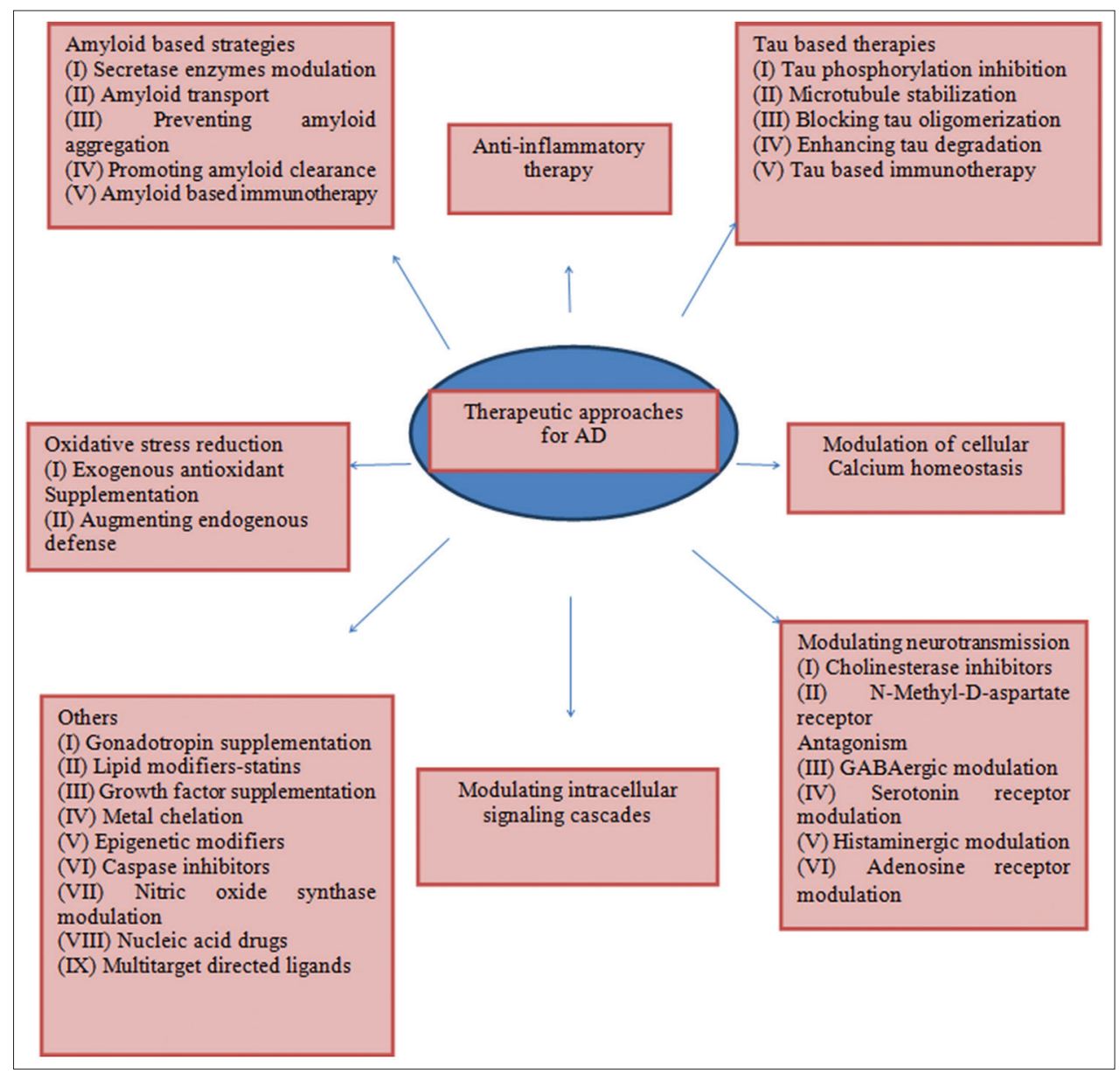

Fig. 4: Obtained from "overview of Alzheimer's disease and some therapeutic approaches targeting A $\beta$ using several synthetic and herbal compounds" 


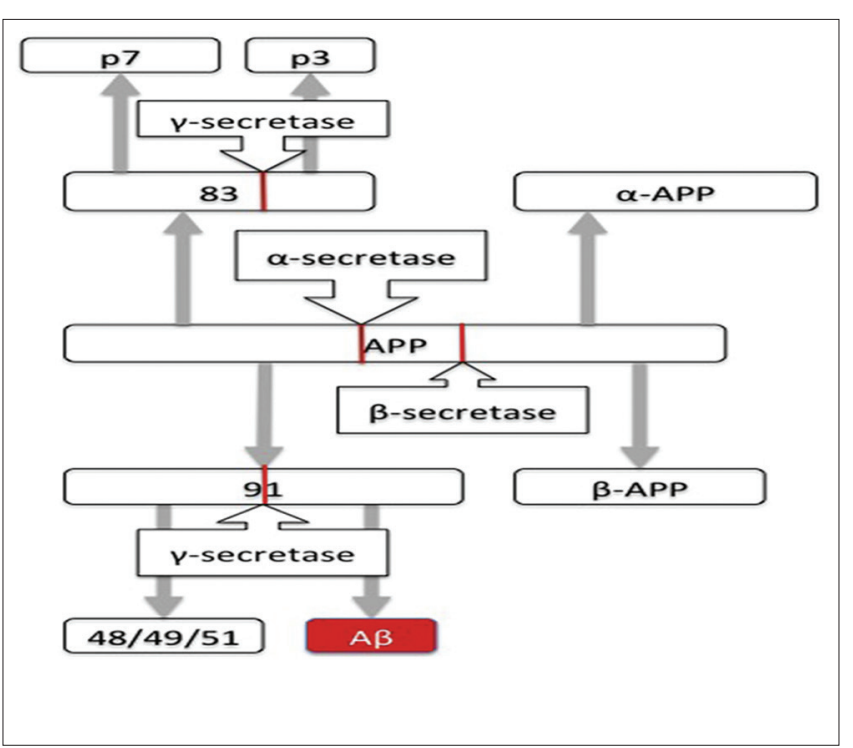

Fig. 5: Obtained from international journal of gerontology "new therapeutic targets in Alzheimer's disease"

moderate $\mathrm{AD}$ who were vaccinated died due to some unknown cause. When examined the brain showed a lack in $\mathrm{A} \beta$ with the maintenance of NFTs. Hence, a passive immunization with preformed $A \beta$ antibodies is developed which prevents the secondary encephalitis [39].

\section{Secretase inhibitors}

The APP is cleaved at $\beta$-secretase cleavage site with the help of aspartyl protease, found to be a predominant $\beta$-cleavage activity in brain. The APP cleaving enzyme which cleaves at specific $\beta$ site is a direct approach in developing pharmacologic agents, which, in turn, inhibits gene expression. $\gamma$-secretase inhibition provides a specific target in inhibiting $A \beta$ synthesis. $\gamma, \beta$ inhibition prevents the $A \beta$ synthesis and also affects the formation of plaques (Fig. 5) [40,41].

\section{Clioquinol}

In a pilot study in patients with $\mathrm{AD}$ metal chelation using clioquinol is reported to reduce the rate of cognitive loss in phase 2 clinical trials. It chelates amyloid plaques associated zinc and copper. The basic therapeutic treatment is the mobilization and removal of brain amyloid [45].

\section{Dietary supplements}

Vitamin B is a supplement, involved in homocysteine metabolism which slows down the progression of AD. Randomized trial showed no effect on cognitive measures. Omega-3-fatty acids along with intake of fish lower the risk of dementia [44].

\section{Strategies of anti-amyloid}

Three secretases are the key action for APP metabolic pathway. The non-amyloid metabolizes involves the proteolysis of APP under the influence of $\alpha$-secretase and forms a soluble fragment $\alpha$-APP along with 83 amino acid - small peptide chain. Further, this smaller chain is cleaved by $\gamma$-secretase to produce two amyloidogenic peptides. Simultaneously, amyloid metabolizes involve the proteolysis of APP using $\beta$-secretase [79]. The resulting fragment is called as $\beta$-APP along with the 91 amino acid - long peptide chain, cleaved by $\gamma$-secretase and releases $A \beta 40, A \beta 42$, and $A \beta 43$ [42].

The anti-amyloid immunotherapy and amyloid aggregation are prevented by $A \beta 42$ reduction which is involved in the metabolism of APP by the inhibition of secretases [43].

APP metabolic pathway. APP = AMYLOID PRECURSOR PROTEIN; $\mathrm{A} \beta=$ AMYLOID-BETA; PROTEIN FRAGMENTS $=48 / 49 / 51,83,91$, p3, p7.
The mutations of APP by FAD gets clustered around the $\alpha, \beta$, and $\gamma$-secretase cleavage sites which induce a change phenotypically while processing the APP and results in increase of A $\beta$ peptide [46].

\section{siRNA gene therapy}

The APP accumulation is the major cause of AD. The APP gene nucleotide sequence is targeted using Accelyrs Gene software to silence the APP gene. pAZLDC1 vector is an efficient treatment of AD [51].

\section{A $\beta$-based therapies}

The production of soluble $A \beta$ monomer is decreased, and the soluble and deposited $A \beta$ is removed. This reduction is attractive because of it; they can be easily titrated down to various concentrations which will not support oligomerization. This production of $A \beta$ from APP forms oligomers and fibrils that have potential targets for anti-amyloid therapies [93].

\section{Other therapeutic approaches}

There are few other therapeutic approaches which shows the results in the treatment of AD. They are: nerve growth factor stimulation, gamma aminobutyric acid receptor modulators, serotonin reputable and somatostatin secretion stimulants, astrocyte modulating agents, phosphodiesterase 4 inhibitors, and cannabinoid agonists.

\section{CONCLUSION}

All the neurodegenerative diseases are age prevalent disorders that occur in many individuals commonly nowadays occurs due to the changes in the molecular mechanisms. There are a lot of evidences for neurodegenerative diseases, arising from oligomeric productions for characterization of diseases, such as AD, PD, and T2DM. Proteins such as amyloid-beta and alpha-synuclein are deleterious to neurons which cause damage to the molecular mechanism. Accumulation of misfolded proteins is associated to human diseases. Protein aggregation lacks the active conformation. In modern inventions elucidating protein misfolding has become the impact for the array of diseases and pathogenesis.

Therapies are likely to be a preventive measure because oligomers grow to form deposits of amyloid fibrils. This assemblies forming is stopped by various diagnostic tools, detecting these fibrils when a patient or an individual suffers with neurodegenerative diseases. Cholinesterase inhibitors are suggested to patients with dementia along with lewy bodies and have greater symptomatic benefits in AD patients. The therapy is not continued in patients who do not appear to be benefiting.

The inhibition of sites in the process is carried out using $A \beta$ is the most challenging therapeutic research. However, anti-A $\beta$ immunotherapy, small molecule secretase inhibitors will be safer therapeutic approach for slowing the progression of disease. Taking into the consideration, the protein - misfolding has been the hot spring for modern scientific investigation, and it impacts the various pathogenesis of wide range of diseases, which includes AD and T2DM.

Including a lot of therapeutic approaches for the treatment of $A D$, seems to be giving a symptomatic therapy which is not believed to be neuroprotective for the underlying disease trajectory.

\section{ACKNOWLEDGMENTS}

We thank DR. M.G.R. Educational and Research Institute for providing us the facilities and their support.

\section{AUTHORS CONTRIBUTION}

Sandhya A contributed for the collection of the article, preparation of manuscript and revising the article. Dr. Gomathi Kannayiram contributed toward revising the article and for the intellectual content. All the authors gave approval for the manuscript.

\section{CONFLICTS OF INTEREST}

None of the authors have any conflicts of interest on this article. 


\section{REFERENCES}

1. Ross CA, Poirier MA. Protein aggregation and neurodegenerative disease. Nat Med 2004;10 Suppl: S10-7.

2. Nussbaum RL, Ellis CE. Alzheimer's disease and Parkinson's disease. N Engl J Med 2003;348:1356-64.

3. Askanas V, Engel WK. Unfolding story of inclusion body myositis and myopathies: Role of misfolded proteins, amyloid-,6, cholesterol, and aging. J Child Neurol 2003;18:185.

4. Cummings BJ, Su JH, Geddes JW, Van Nostrand WE, Wagner SL, Cunningham DD, et al. Aggregation of the amyloid precursor protein within degenerating neurons and dystrophic neurites in Alzheimer's disease. Neuroscience 1992;48:763-77.

5. Ballew RM, Sabelko J, Gruebele M. Direct observation of fast protein folding: The initial collapse of apomyoglobin. Proc Natl Acad Sci U S A 1996;93:5759-64.

6. Ross CA, Pickart CM. The ubiquitin-proteasome pathway in Parkinson's disease and other neurodegenerative diseases. Trends Cell Biol 2004; 14:703-11.

7. Forloni G, Iussich S, Awan T, Colombo L, Angeretti N, Girola L, et al. Tetracyclines affect prion infectivity. Proc Natl Acad Sci U S A 2002;99:10849-54

8. Dobson CM. Protein chemistry. In the footsteps of alchemists. Science 2004;304:1259-62.

9. Kelly JW. Structural biology: Proteins downhill all the way. Nature 2006;442:255-6.

10. Wong PC, Cai H, Borchelt DR, Price DL. Genetically engineered mouse models of neurodegenerative diseases. Nat Neurosci 2002;5:633-9.

11. Ballatore C, Lee VM, Trojanowski JQ. Tau-mediated neurodegeneration in Alzheimer's disease and related disorders. Nat Rev Neurosci 2007;8:663-72.

12. Fink AL. Protein aggregation: Folding aggregates, inclusion bodies and amyloid. Fold Des 1998;3:R9-23.

13. Soto C. Unfolding the role of protein misfolding in neurodegenerative diseases. Nat Rev Neurosci 2003;4:49-60

14. Wu C, Shea JE. Structural similarities and differences between amyloidogenic and non-amyloidogenic islet amyloid polypeptide (IAPP) sequences and implications for the dual physiological and pathological activities of these peptides. PLoS Comput Biol 2013;9:e1003211

15. Ferri CP, Prince M, Brayne C, Brodaty H, Fratiglioni L, Ganguli M, et al. Global prevalence of dementia: A Delphi consensus study. Lancet 2005;366:2112-7.

16. Bentahir M, Nyabi O, Verhamme J, Tolia A, Horré K, Wiltfang J, et al. Presenilin clinical mutations can affect gamma-secretase activity by different mechanisms. J Neurochem 2006;96:732-42.

17. Iwatsubo T, Odaka A, Suzuki N, Mizusawa H, Nukina N, Ihara Y, et al. Visualization of A beta $42(43)$ and A beta 40 in senile plaques with end-specific A beta monoclonals: Evidence that an initially deposited species is A beta 42(43). Neuron 1994;13:45-53.

18. Mathis CA, Klunk WE, Price JC, DeKosky ST. Imaging technology for neurodegenerative diseases: Progress toward detection of specific pathologies. Arch Neurol 2005;62:196-200.

19. Masters CL, Simms G, Weinman NA, Multhaup G, McDonald BL, Beyreuther $\mathrm{K}$, et al. Amyloid plaque core protein in Alzheimer disease and down syndrome. Proc Natl Acad Sci U S A 1985;82:4245-9.

20. Lemere CA, Blusztajn JK, Yamaguchi H, Wisniewski T, Saido TC, Selkoe DJ, et al. Sequence of deposition of heterogeneous amyloid beta-peptides and APO E in down syndrome: Implications for initial events in amyloid plaque formation. Neurobiol Dis 1996;3:16-32.

21. de Leon MJ, DeSanti S, Zinkowski R, Mehta PD, Pratico D, Segal S, et al. MRI and CSF studies in the early diagnosis of Alzheimer's disease. J Intern Med 2004;256:205-23.

22. Masdeu JC, Zubieta JL, Arbizu J. Neuroimaging as a marker of the onset and progression of Alzheimer's disease. J Neurol Sci 2005;236:55-64.

23. McKhann GM, Knopman DS, Chertkow H, Hyman BT, Jack CR Jr. Kawas CH, et al. The diagnosis of dementia due to Alzheimer's disease: Recommendations from the national institute on agingAlzheimer's association workgroups on diagnostic guidelines for Alzheimer's disease. Alzheimers Dement 2011;7:263-9.

24. Orrego F, Villanueva S. The chemical nature of the main central excitatory transmitter: A critical appraisal based upon release studies and synaptic vesicle localization. Neuroscience 1993;56:539-55.

25. Doody RS, Stevens JC, Beck C, Dubinsky RM, Kaye JA, Gwyther L, et al. Practice parameter: Management of dementia (an evidence- based review).

Report

of

American academy of neurology. Neurology 2001;56:1154-66.

26. Trinh NH, Hoblyn J, Mohanty S, Yaffe K. Efficacy of cholinesterase inhibitors in the treatment of neuropsychiatric symptoms and functional impairment in Alzheimer disease: A meta-analysis. JAMA 2003;289:210-6.

27. Birks J. Cholinesterase inhibitors for Alzheimer's disease. Cochrane Database Syst Rev 2006;2006:CD005593.

28. Birks JS, Grimley Evans J. Rivastigime for Alzheimer's disease. Cochrane Database Syst Rev 2015;2015:CD001191.

29. Birks J, Harvey RJ. Donepezil for dementia due to Alzheimer's disease. Cochrane Database Syst Rev 2006;2006:CD001190.

30. Howard R, McShane R, Lindesay J, Ritchie C, Baldwin A, Barber R, et al. Donepezil and memantine for moderate-to-severe Alzheimer's disease. N Engl J Med 2012;366:893.

31. Henderson VW. Estrogen, cognition, and a women's risk of Alzheimer's disease. Am J Med 1997;103:11S

32. Shumaker SA, Legault C, Kuller L, Rapp SR, Thal L, Lane DS, et al. Conjugated equine estrogens and incidence of probable dementia and mild cognitive impairment in postmenopausal women: Women's health initiative memory study. JAMA 2004;291:2947-58.

33. Farina N, Llewellyn D, Issac MG, Tabet N. Vitamin E for Alzheimer's dementia and mild cognitive impairment. Cochrane Database Syst Rev 2017;1:CD002854.

34. Sano M, Ernesto C, Thomas RG, Klauber MR, Schafer K, Grundman M, et al. A controlled trial of selegiline, alpha-tocopherol, or both as treatment for Alzheimer's disease. The Alzheimer's disease cooperative study. N Engl J Med 1997;336:1216-22.

35. Rogers J, Webster S, Lue LF, Brachova L, Civin WH, Emmerling M, et al. Inflammation and Alzheimer's disease pathogenesis. Neurobiol Aging 1996;17:681-6.

36. Andersen K, Launer LJ, Ott A, Hoes AW, Breteler MM, Hofman A, et al. Do nonsteroidal anti-inflammatory drugs decrease the risk for Alzheimer's disease? The Rotterdam study. Neurology 1995;45:1441-5.

37. Sparks DL, Sabbagh MN, Connor DJ, Lopez J, Launer LJ, Browne P, et al. Atorvastatin for the treatment of mild to moderate Alzheimer disease: Preliminary results. Arch Neurol 2005;62:753-7.

38. Feldman HH, Doody RS, Kivipelto M, Sparks DL, Waters DD, Jones RW, et al. Randomized controlled trial of atorvastatin in mild to moderate Alzheimer disease: LEADe. Neurology 2010;74:956-64.

39. Wisniewski T, Boutajangout A. Vaccination as a therapeutic approach to Alzheimer's disease. Mt Sinai J Med 2010;77:17-31.

40. Panza F, Frisardi V, Solfrizzi V, Imbimbo BP, Logroscino G, Santamato A, et al. Interacting with $\gamma$-secretase for treating Alzheimer's disease: From inhibition to modulation. Curr Med Chem 2011;18:5430-47.

41. Eriksen JL, Sagi SA, Smith TE, Weggen S, Das P, McLendon DC, et al. NSAIDs and enantiomers of flurbiprofen target gamma-secretase and lower abeta 42 in vivo. J Clin Invest 2003;112:440-9.

42. Selkoe DJ. Clearing the brain's amyloid cobwebs. Neuron 2001;32:177-80.

43. Montoliu-Gaya L, Villegas S. Protein structures in Alzheimer's disease: The basis for rationale therapeutic design. Arch Biochem Biophys 2015;588:1-4.

44. Aisen PS, Schneider LS, Sano M, Diaz-Arrastia R, van Dyck CH, Weiner MF, et al. High-dose B vitamin supplementation and cognitive decline in Alzheimer disease: A randomized controlled trial. JAMA 2008;300:1774-83.

45. Regland B, Lehmann W, Abedini I, Blennow K, Jonsson M, Karlsson I, et al. Treatment of Alzheimer's disease with clioquinol. Dement Geriatr Cogn Disord 2001;12:408-14

46. Selkoe DJ. The cell biology of beta-amyloid precursor protein and Presenilin in Alzheimer's disease. Trends Cell Biol 1998;8:447-53.

47. Glenner GG, Wong CW. Alzheimer's disease: Initial report of the purification and characterization of a novel cerebrovascular amyloid protein. Biochem Biophys Res Commun 1984;120:885-90.

48. Thal DR, Capetillo-Zarate E, Del Tredici K, Braak H. The development of amyloid beta protein deposits in the aged brain. Sci Aging Knowledge Environ 2006;2006:re1.

49. Meda L, Baron P, Scarlato G. Glial activation in Alzheimer's disease: The role of abeta and its associated proteins. Neurobiol Aging 2001;22:885-93.

50. Kiranjit K, Rajneet K, Manjinder K. Recent advances in Alzheimer's disease: Cause and treatment. Intl J Pharm Pharm Sci 2016;8:8-15.

51. Ambili TR, Manimekalan A, Abhijith BD. SiRNA gene therapy for Alzheimer's disease targeting APP gene. Intl J Pharm Pharm Sci 2012;4:341-6.

52. Ross CA, Poirier MA. Protein aggregation and neurodegenerative 
disease. Nat Med 2004;10 Suppl: S10-7.

53. Jakob-Roetne R, Jacobsen H. Alzheimer's disease: From pathology to therapeutic approaches. Angew Chem Int Ed Engl 2009;48:3030-59.

54. Scott LE, Orvig C. Medicinal inorganic chemistry approaches to passivation and removal of aberrant metal ions in disease. Chem Rev 2009;109:4885-910.

55. Bonda DJ, Lee HG, Blair JA, Zhu X, Perry G, Smith MA. Role of metal dyshomeostasis in Alzheimer's disease. Metallomics 2011;3:267-70.

56. Bush AI, Tanzi RE. Therapeutics for Alzheimer's disease based on the metal hypothesis. Neurotherapeutics 2008;5:421-32.

57. Rauk A. The chemistry of Alzheimer's disease. Chem Soc Rev 2009;38:2698-715

58. Dobson CM. Protein misfolding and degenerative diseases. Nat Educ 2010;3:28.

59. Gaggelli E, Kozlowski H, Valensin D, Valensin G. Copper homeostasis and neurodegenerative disorders (Alzheimer's, prion and Parkinson's diseases and amyotrophic lateral sclerosis). Chem Rev 2006;106:1995-2044.

60. Haass C, Selkoe DJ. Soluble protein oligomers in neurodegeneration: Lessons from Alzheimer's amyloid beta-peptide. Nat Rev Mol Cell Biol 2007;8:101-12.

61. Lichtenthaler SF, Haass C, Steiner H. Regulated intramembrane proteolysis-lessons from amyloid precursor protein processing. J Neurochem 2011;117:779-96.

62. Stefani M, Dobson CM. Protein aggregation and aggregate toxicity: New insights into protein folding, misfolding diseases and biological evolution. J Mol Med (Berl) 2003;81:678-99.

63. Stefani M. Generic cell dysfunction in neurodegenerative disorders: Role of surfaces in early protein misfolding, aggregation, and aggregate cytotoxicity. Neuroscientist 2007;13:519-31.

64. Davidowitz EJ, Chatterjee I, Moe GS. Targetting tau oligomers for therapeutic development for Alzheimer's disease and tauopathies. Curr Topics Biotechnol 2008;4:47-64

65. Berger Z, Roder H, Hanna A, Carlson A, Rangachari V, Yue M, et al. Accumulation of pathological tau species and memory loss in a conditional model of tauopathy. J Neurosci 2007;27:3650-62.

66. Irwin DJ, Lee VM, Trojanowski JQ. Parkinson's disease dementia: Convergence of $\alpha$-synuclein, tau and amyloid- $\beta$ pathologies. Nat Rev Neurosci 2013;14:626-36.

67. Gómez-Ramos A, Díaz-Hernández M, Cuadros R, Hernández F, Avila J. Extracellular tau is toxic to neuronal cells. FEBS Lett 2006;580:4842-50.

68. Gómez-Ramos A, Díaz-Hernández M, Rubio A, Miras-Portugal MT, Avila J. Extracellular tau promotes intracellular calcium increase through M1 and M3 muscarinic receptors in neuronal cells. Mol Cell Neurosci 2008;37:673-81.

69. Cuanalo-Contreras K, Mukherjee A, Soto C. Role of protein misfolding and proteostasis deficiency in protein misfolding diseases and aging. Int J Cell Biol 2013;2013:638083.

70. Harper JD, Lansbury PT Jr. Models of amyloid seeding in Alzheimer's disease and scarpie: Mechanistic truths and physiological consequences of the time-dependent solubility of amyloid proteins. Annu Rev Biochem 1997;66:385-407.

71. Muoio DM, Newgard CB. Molecular and metabolic mechanisms of insulin resistance and $\beta$-cell failure in Type 2 diabetes. Nat Rev Mol Cell Biol 2008;9:193-205.

72. Kirkman MS, Briscoe VJ, Clark N, Florez H, Haas LB, Halter JB, et al. Diabetes in older adults: A consensus report. J Am Geriatr Soc 2012;60:2342-56.

73. Action to Control Cardiovascular Risk in Diabetes Study Group, Gerstein HC, Miller ME, Byington RP, Goff DC Jr. Bigger JT, et al. Effects of intensive glucose lowering in Type 2 diabetes. N Engl J Med 2008;358:2545-59.

74. Höppener JW, Ahrén B, Lips CJ. Islet amyloid and Type 2 diabetes mellitus. N Engl J Med 2000;343:411-9.

75. Abedini A, Schmidt AM. Mechanisms of islet amyloidosis toxicity in Type 2 diabetes. FEBS Lett 2013;587:1119-27.

76. Pillay K, Govender P. Amylin uncovered: A review on the polypeptide responsible for Type II diabetes. Biomed Res Int 2013;2013:826706.

77. Cao P, Tu LH, Abedini A, Levsh O, Akter R, Patsalo V, et al. Sensitivity of amyloid formation by human islet amyloid polypeptide to mutations at residue 20. J Mol Biol 2012;421:282-95.

78. Hayden MR. Islet amyloid, metabolic syndrome, and the natural progressive history of Type 2 diabetes mellitus. JOP 2002;3:126-38.
79. De Lorenzi E, Giorgetti S, Grossi S, Merlini G, Caccialanza G, Bellotti V, et al. Pharmaceutical strategies against amyloidosis: Old and new drugs in targeting a "protein misfolding disease". Curr Med Chem 2004; 11:1065-84

80. Dandona P, Thusu K, Cook S, Snyder B, Makowski J, Armstrong D, et al. Oxidative damage to DNA in diabetes mellitus. Lancet 1996;347:444-5

81. Lemere CA, Oh J, Stanish HA, Peng Y, Pepivani I, Fagan AM, et al. Cerebral amyloid-beta protein accumulation with aging in cotton-top tamarins: A model of early Alzheimer's disease? Rejuvenation Res 2008;11:321-32.

82. Janson J, Laedtke T, Parisi JE, O'Brien P, Petersen RC, Butler PC, et al. Increased risk of Type 2 diabetes in Alzheimer disease. Diabetes 2004:53:474-81.

83. Li W, Prakash R, Kelly-Cobbs AI, Ogbi S, Kozak A, El-Remessy AB, et al. Adaptive cerebral neovascularization in a model of Type 2 diabetes: Relevance to focal cerebral ischemia. Diabetes 2010;59:228-35.

84. ElAli A, Thériault P, Préfontaine P, Rivest S. Mild chronic cerebral hypoperfusion induces neurovascular dysfunction, triggering peripheral beta-amyloid brain entry and aggregation. Acta Neuropathol Commun 2013;1:75.

85. Mukherjee E, Carroll R, Matfin G. Endocrine and metabolic emergencies: Hypoglycaemia. Ther Adv Endocrinol Metab 2011;2:81-93.

86. Hachinski V, Iadecola C, Petrsen RC, Breteler MM, Nyenhuis DL, Black SE, et al. National institute of neurological disorders and stroke-Canadian stroke network vascular cognitive imapirment harmonization standards. Stroke 2006;37:2220-41.

87. Abramov E, Dolev I, Fogel H, Ciccotosto GD, Ruff E, Slutsky I, et al. Amyloid-beta as a positive endogenous regulator of release probability at hippocampal synapses. Nat Neurosci 2009;12:1567-76.

88. Morley JE, Farr SA. The role of amyloid-beta in the regulation of memory. Biochem Pharmacol 2014;88:479-85.

89. Lam AR, Rodriguez JJ, Rojas A, Scheraga HA, Mukamel S. Tracking the mechanism of fibril assembly by simulated two-dimensional ultraviolet spectroscopy. J Phys Chem A 2013;117:342-50.

90. De Felice FG, Ferreira ST. Inflammation, defective insulin signalling, and mitochondrial dysfunction as common molecular denominators connecting Type 2 diabetes to Alzheimer disease. Diabetes 2014;63:2262-72.

91. Talbot K, Wang HY, Kazi H, Han LY, Bakshi KP, Stucky A, et al. Demonstrated brain insulin resistance in Alzheimer's disease patients is associated with IGF-1 resistance, IRS-1 dysregulation, and cognitive decline. J Clin Invest 2012;122:1316-38.

92. Talbot K, Wang HY. The nature, significance, and glucagon-like peptide-1 analog treatment of brain insulin resistance in Alzheimer's disease. Alzheimers Dement 2014;10:S12-25.

93. Schenk D, Barbour R, Dunn W, Gordon G, Grajeda H, Guido T, et al. Immunization with amyloid-beta attenuates Alzheimer-disease-like pathology in the PDAPP mouse. Nature 1999;400:173-7.

94. Strittmatter WJ, Weisgraber KH, Huang DY, Dong LM, Salvesen GS, Pericak-Vance $\mathrm{M}$, et al. Binding of human apolipoprotein $\mathrm{E}$ to synthetic amyloid beta peptide: Isoform-specific effects and implications for late-onset Alzheimer disease. Proc Natl Acad Sci U S A 1993;90:8098-102.

95. Saunders AM, Strittmatter WJ, Schmechel D, George-Hyslop PH, Pericak-Vance MA, Joo SH, et al. Association of apolipoprotein E allele epsilon 4 with late-onset familial and sporadic Alzheimer's disease. Neurology 1993;43:1467-72.

96. Martin ER, Scott WK, Nance MA, Watts RL, Hubble JP, Koller WC, et al. Association of single-nucleotide polymorphisms of the tau gene with late-onset Parkinson disease. JAMA 2001;286:2245-50.

97. Cole N, Siddique T. Genetic disorders of motor neurons. Semin Neurol 1999;19:407-18.

98. Giasson BI, Forma MS, Higuchi M, Golbe LI, Graves CL, Kotzbauer PT, Trojanowski JQ, and Lee VM. Sciences2 003; 300(5619): $636-40$

99. Gatz M, Reynolds CA, Fratiglioni L, Johansson B, Mortimer JA, Berg S, et al. Role of genes and environments for explaining Alzheimer disease. Arch Gen Psychiatry 2006;63:168-74.

100. Klunk WE, Engler H, Nordberg A, Wang Y, Blomqvist G, Holt DP, et al. Imaging brain amyloid in Alzheimer's disease with Pittsburgh compound-B. Ann Neurol 2004;55:306-19. 